\title{
Paeoniflorin attenuates ultraviolet B-induced apoptosis in human keratinocytes by inhibiting the ROS-p38-p53 pathway
}

\author{
LINGWEN KONG $^{1 *}$, SHANGSHANG WANG $^{2 *}, \mathrm{XIAO} \mathrm{WU}^{1 *}$, FUGUO ZUO $^{3}$, HAIHONG QIN $^{2}$ and JINFENG WU ${ }^{2}$ \\ Departments of ${ }^{1}$ Integrative Medicine and ${ }^{2}$ Dermatology, Huashan Hospital, Fudan University, Shanghai 200040; \\ ${ }^{3}$ Department of Dermatology, East Hospital, Tongji University School of Medicine, Shanghai 200120, P.R. China
}

Received March 26, 2015; Accepted January 13, 2016

DOI: $10.3892 / \mathrm{mmr} .2016 .4953$

\begin{abstract}
Ultraviolet (UV) light is one of the most harmful environmental factors that contribute to skin damage. Exposure to UV induces extensive generation of reactive oxygen species (ROS), and results in photoaging and skin cancer development. One approach to protecting human skin against UV radiation is the use of antioxidants. In recent years, naturally occurring herbal compounds have gained considerable attention as protective agents for UV exposure. Paeoniflorin (PF) is a novel natural antioxidant, which is isolated from peony root (Radix Paeoniae Alba). The present study evaluated the protective effects of PF on UV-induced skin damage in vitro, and demonstrated that the effects were mediated via the ROS-p38-p53 pathway. The results of the present study demonstrated that treatment with PF $(25,50$, and $100 \mu \mathrm{M})$ significantly increased the percentage of viable keratinocytes after UV-B exposure. In addition, cell death analysis indicated that $\mathrm{PF}$ treatment markedly reduced UV-B-radiation-induced apoptosis in keratinocytes, which was accompanied by increased procaspase 3 expression and decreased cleaved caspase 3 expression. Treatment with PF markedly reduced the production of ROS, and inhibited the activation of p38 and p53 in human keratinocytes, thus suggesting that the ROS-p38-p53 pathway has a role in UV-B-induced skin damage. In conclusion, the present study reported that PF was able to attenuate UV-B-induced cell damage in human keratinocytes. Notably, these effects were shown to be mediated, at least in part, via inhibition of the ROS-p38-p53 pathway.
\end{abstract}

\section{Introduction}

Exposure to ultraviolet (UV) light, particularly UV-B $(290-320 \mathrm{~nm})$, is a major etiological factor that contributes to

Correspondence to: Dr Jinfeng Wu, Department of Dermatology, Huashan Hospital, Fudan University, 12 Middle Urumqi Road, Shanghai 200040, P.R. China

E-mail: wujinfeng21@163.com

"Contributed equally

Key words: paeoniflorin, ultraviolet, skin, ROS, p38, p53 skin damage (1). Intense and chronic UV exposure is associated with sunburn, immune suppression, DNA damage, photoaging, and skin cancer $(2,3)$. UV can be directly absorbed by cellular macromolecules, thus leading to photochemical modification of DNA and proteins (4). In addition, UV induces the generation of reactive oxygen species (ROS), which overwhelm the antioxidant defense system, resulting in oxidative stress and damage to cell structure, DNA, proteins and lipids (5).

UV-B-induced DNA damage can trigger cell signaling pathways to activate defense systems, leading to DNA repair and/or apoptosis (6). Among these cell-signaling proteins, activation of p53 is important in cells with UV radiation-induced DNA damage $(4,7)$. In addition, oxidative stress is associated with UV-induced activation of p53 (4). Pretreatment of cells with $\mathrm{N}$-acetyl-L-cysteine (NAC), an agent known to counteract oxidative stress, attenuates the cellular p53 response to UV (4). Mitogen-activated protein kinases (MAPKs) are also involved in the response to UV radiation (8); p38 acts as a stress-activated MAPK that is preferentially activated by diverse cellular stressors, including UV-B-induced oxidative stress (9). It has previously been reported that p38 mediates $\mathrm{UV}$-induced phosphorylation of p53. Pretreatment of cells with SB202190, a p38 inhibitor, may inhibit the DNA binding activity of p53 and suppress p53-dependent transcription (10). These previous results indicated that the ROS-p38-p53 pathways are involved in $\mathrm{UV}$-induced cell damage.

UV-B-induced skin damage may be prevented by avoidance of intense sun exposure, as well as topical and systemic administration of antioxidants (11). Peony root (Radix Paeoniae Alba) is a well-known herb, which has been used in Chinese medicine for $>1,200$ years (12). Several compounds, including paeoniflorin (PF), albiflorin, oxypaeoniflorin and benzoylpaeoniflorin, are reported to be contained within peony root (13). Among them, PF is considered to be one of the major bioactive components (13). PF has been reported to exert anti-inflammatory (12), antioxidative (14) and antitumor effects (15). Extracts of peony root have previously been shown to exert protective effects against UV-induced DNA damage and facial wrinkles in human skin (16). However, the anti-UV effects of purified PF have yet to be elucidated.

The present study evaluated the protective effects of PF on $\mathrm{UV}$-induced skin damage in vitro, and demonstrated that the effects were mediated via the ROS-p38-p53 pathway. 


\section{Materials and methods}

Reagents and cell culture. PF (purity>99.8\%; Fig. 1A) was purchased from Chengdu Mansite Pharmaceutical Co., Ltd. (Chengdu, China). The HaCaT human keratinocyte cells were purchased from the China Center for Type Culture Collection (Wuhan, China), and were cultured in Dulbecco's modified Eagle's medium (DMEM; Invitrogen; Thermo Fisher Scientific, Inc., Waltham, MA, USA) supplemented with $4 \mathrm{mM}$ L-glutamine, $3.7 \mathrm{~g} / 1$ sodium bicarbonate, $4.5 \mathrm{~g} / 1$ glucose and $10 \%$ fetal bovine serum (Invitrogen; Thermo Fisher Scientific, Inc.). Cells were maintained in a humidified incubator containing $5 \% \mathrm{CO}_{2}$ at $37^{\circ} \mathrm{C}$. WST- 8 was obtained from Dojindo Molecular Technologies, Inc. (Kumamoto, Japan). Propidium iodide (PI) and RNase A were purchased from Beyotime Institute of Biotechnology (Haimen, China). Antibodies against phosphorylated (P)-p38 (cat. no. 4511), p38 (cat. no. 8690), P-p53 (cat. no. 9284), p53 (cat. no. 2524), caspase 3 (cat. no. 9662), cleaved caspase 3 (cat. no. 9664) and $\beta$-actin (cat. no. 8457) were obtained from Cell Signaling Technology, Inc. (Danvers, MA, USA). NAC and SB203580 were purchased from Sigma-Aldrich (St. Louis, MO, USA).

$U V$ radiation. $\mathrm{HaCaT}$ cells were pretreated with various concentrations of $\mathrm{PF}(0,25,50$ and $100 \mu \mathrm{M})$ for $2 \mathrm{~h}$ in serum-free medium. Subsequently, the cells were washed with phosphate-buffered saline (PBS) and covered with a thin layer of PBS. UV-B radiation was applied at a level of $60 \mathrm{~mJ} / \mathrm{cm}^{2}$ using a Philips TL-D/08 15W weathering lamp (wavelength 290-340 nm, peak $311 \mathrm{~nm}$ ) (Philips, Amsterdam, The Netherlands). The radiation intensity was monitored using a UV-B radiometer (Beijing Normal University, Beijing, China). Following exposure to UV-B radiation, PBS was removed and DMEM containing PF $(0,25,50$ or $100 \mu \mathrm{M})$ was added to the cells, which were incubated at $37^{\circ} \mathrm{C}$ for a suitable period.

Cell viability assays. PF [dissolved in dimethyl sulfoxide (DMSO)] was used to treat the cells. The final concentration of DMSO used was $<0.1 \%(\mathrm{v} / \mathrm{v})$. Cell viability was measured using the WST-8 assay (Dojindo Molecular Technologies, Inc.), according to the manufacturer's protocol. Briefly, $\mathrm{HaCaT}$ cells were seeded at a density of $5 \times 10^{3}$ cells/well in 96-well culture plates in DMEM, and were cultured in a humidified incubator at $37^{\circ} \mathrm{C}$ overnight. The cells were pretreated with $\operatorname{PF}(0,25,50$, and $100 \mu \mathrm{M}$ ) for $2 \mathrm{~h}$. Following UV-B radiation, the cells were incubated for a further $24 \mathrm{~h}$, after which, $10 \mu \mathrm{l}$ WST- 8 was added to each well for $1 \mathrm{~h}$. Subsequently, optical density (OD) was measured at a wavelength of $450 \mathrm{~nm}$ using a BIO-TEK MQX200 plate reader (Highland Park Efficiencies, Winooski, VT, USA). The percentage of viable cells was determined using the following formula: Ratio $(\%)=[\mathrm{OD}(\mathrm{PF})-\mathrm{OD}($ Blank $) / \mathrm{OD}($ Control $)-\mathrm{OD}$ (Blank)] x 100. Cell viability data are averages of three independent experiments each containing six replicates.

Cell death analysis. HaCaT cells were seeded at a density of $2 \times 10^{5}$ cells/well in 6-well culture plates in DMEM, and were cultured in a humidified incubator at $37^{\circ} \mathrm{C}$ for $24 \mathrm{~h}$. The cells were pretreated with $25 \mu \mathrm{M}$ PF for $2 \mathrm{~h}$. Following UV-B radiation, the cells were incubated for a further $24 \mathrm{~h}$, after which, cells were collected and fixed in $70 \%$ ethanol for $24 \mathrm{~h}$ at $4^{\circ} \mathrm{C}$.
A

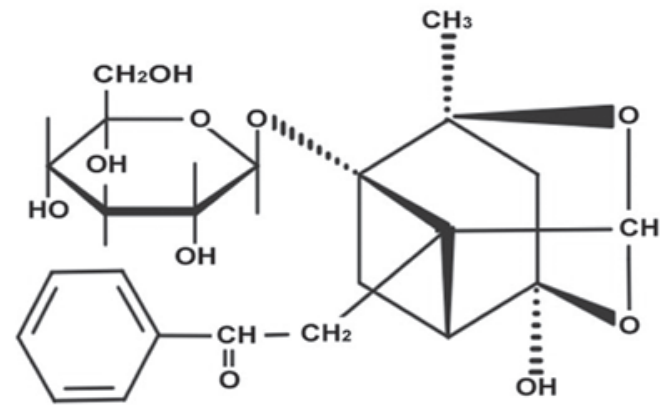

Chemical structure of paeoniflorin

B

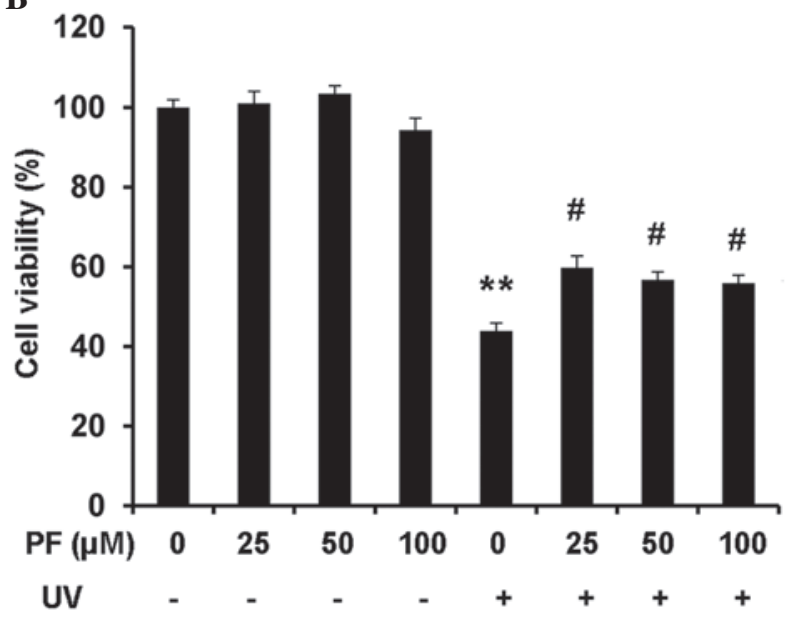

Figure 1. PF attenuated UV-B-induced decreased cell viability in $\mathrm{HaCaT}$ cells. (A) Chemical structure of PF. (B) Cell viability of HaCaT cells as measured by the WST- 8 assay. Cells were pretreated with PF $(0,25,50$, and $100 \mu \mathrm{M})$ for $2 \mathrm{~h}$. Following UV-B $\left(60 \mathrm{~mJ} / \mathrm{cm}^{2}\right)$ radiation, the cells were incubated for $24 \mathrm{~h}$, after which, $10 \mu \mathrm{l}$ WST- 8 was added to each well for $1 \mathrm{~h}$. Optical density was measured at $450 \mathrm{~nm}$ using a plate reader. Data are presented as the mean \pm standard deviation. ${ }^{* *} \mathrm{P}<0.01$, compared with the medium control group; ${ }^{\prime} \mathrm{P}<0.01$, compared with UV-B exposure alone. $\mathrm{PF}$, paeoniflorin; UV, ultraviolet.

Subsequently, the cells were centrifuged at $300 \mathrm{x} \mathrm{g}$ for $5 \mathrm{~min}$ and the cell pellet was resuspended in $400 \mu \mathrm{l}$ PBS containing RNase A $(10 \mathrm{mg} / \mathrm{ml}, 50 \mu \mathrm{l})$ and PI $(2 \mathrm{mg} / \mathrm{ml}, 10 \mu \mathrm{l})$. The mixture was incubated in the dark at $37^{\circ} \mathrm{C}$ for $30 \mathrm{~min}$ and data were acquired using a FACSCalibur flow cytometer (BD Biosciences, San Joe, CA, USA). The cell death data were analyzed using FlowJo software V6.0 (Tree Star, Inc., Ashland, OR, USA). The extent of cell death was determined by evaluating the sub $\mathrm{G}_{1}$ fraction, or the percentage of cells with DNA content $<2 n$. The experiment was replicated three times.

Western blot analysis. HaCaT cells were seeded at a density of $5 \times 10^{5}$ cells/well in 6-well culture plates in DMEM, and were cultured in a humidified incubator at $37^{\circ} \mathrm{C}$ for $24 \mathrm{~h}$. The cells were pretreated with $25 \mu \mathrm{M}$ PF or $5 \mu \mathrm{M}$ SB203580 for $2 \mathrm{~h}$. Following UV-B radiation, the cells were incubated for a further $24 \mathrm{~h}$, after which, cells were collected and resuspended in lysis buffer $[150 \mathrm{mmol} / 1 \mathrm{NaCl}, 1 \% \mathrm{NP}-40$, $0.5 \%$ sodium deoxycholate, $0.1 \%$ sodium dodecyl sulfate (SDS), $50 \mathrm{mmol} / 1$ Tris-Cl, $\mathrm{pH} 8.0]$ containing $2 \mu \mathrm{g} / \mathrm{ml}$ aprotinin, $2 \mu \mathrm{g} / \mathrm{ml}$ leupeptin $40 \mathrm{mg} / \mathrm{ml}$ phenylmethylsulfonyl fluoride and $2 \mathrm{mmol} / \mathrm{l}$ DTT. The cells were centrifuged at 
A
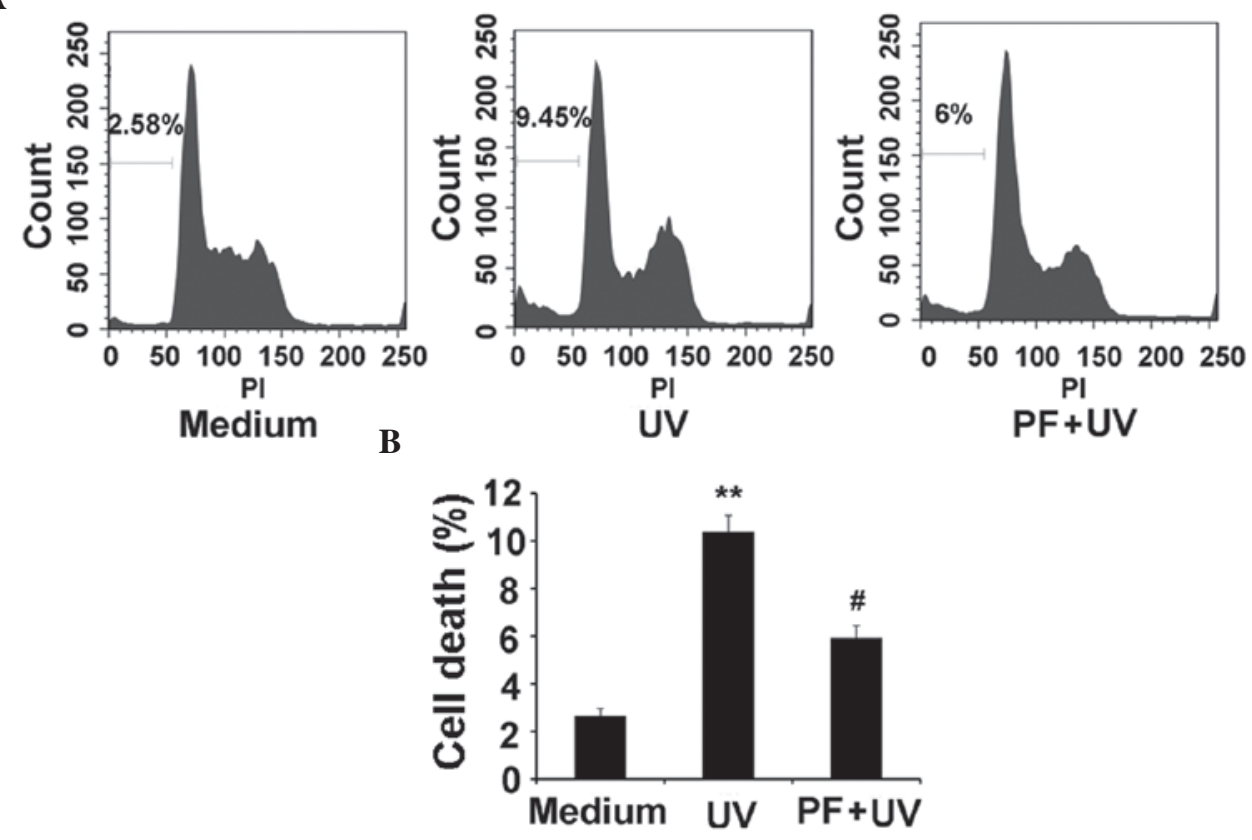

Figure 2. PF reduced UV-B-induced cell death in HaCaT cells. The cells were pretreated with $25 \mu \mathrm{M}$ PF for $2 \mathrm{~h}$. Following UV-B $\left(60 \mathrm{~mJ} / \mathrm{cm}^{2}\right) \mathrm{radiation}$, the cells were incubated for $24 \mathrm{~h}$, after which, the cells were fixed and stained with PI. Data were acquired using a FACSCalibur flow cytometer and were analyzed using FlowJo software V6.0. (A) Representative images of cell death assays. (B) Statistical analysis of cell death assays. Cell death assays were replicated three times. Data are presented as the mean \pm standard deviation. ${ }^{* *} \mathrm{P}<0.01$, compared with the medium control group; ${ }^{*} \mathrm{P}<0.01$, compared with UV-B exposure alone. PF, paeoniflorin; UV, ultraviolet; PI, propidium iodide.

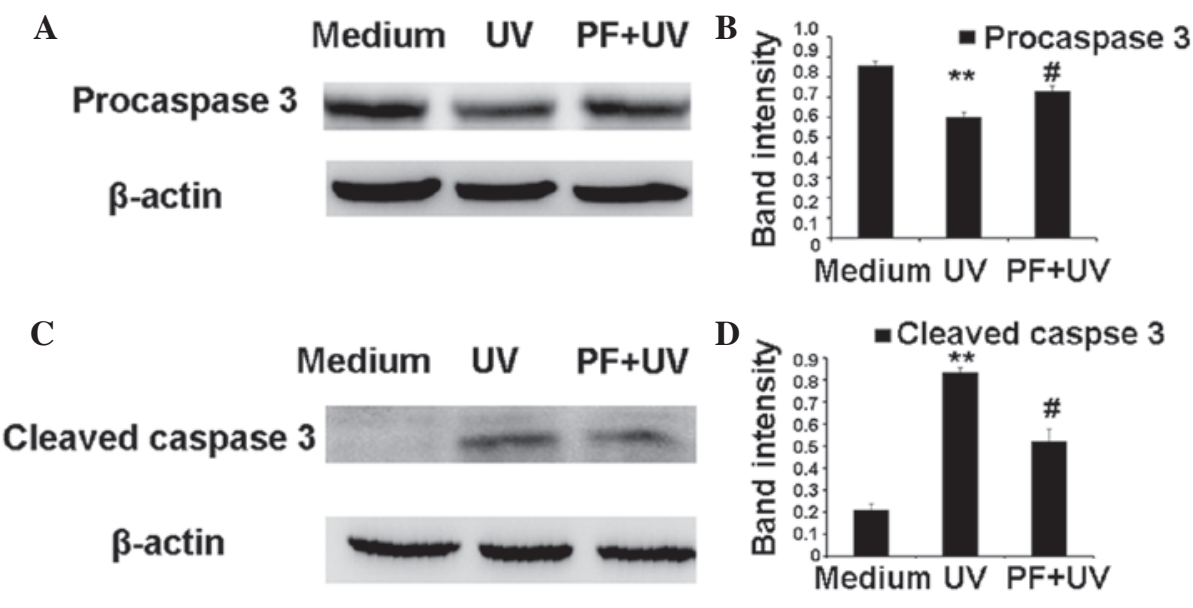

Figure 3. PF treatment counteracted the effects of UV-B on procaspase 3 and cleaved caspase 3 . The cells were pretreated with $25 \mu \mathrm{M}$ PF for $2 \mathrm{~h}$. Following UV-B $\left(60 \mathrm{~mJ} / \mathrm{cm}^{2}\right)$ radiation, the cells were incubated for $24 \mathrm{~h}$, after which, procaspase 3 and cleaved caspase 3 expression were detected by western blotting. All lanes were loaded with $30 \mu \mathrm{g}$ protein and $\beta$-actin was used as a loading control. Band intensities were quantified using UN-SCAN-IT gel analysis software. Optical density for target proteins was indicated as a proportion of $\beta$-actin optical density. (A) Representative western blot of procaspase 3. (B) Quantification of band intensities of procaspase 3. (C) Representative western blot of cleaved caspase 3. (D) Quantification of band intensities of cleaved caspase 3. Data are presented as the mean \pm standard deviation. ${ }^{* *} \mathrm{P}<0.01$, compared with the medium control group; ${ }^{*} \mathrm{P}<0.01$, compared with UV-B exposure alone. $\mathrm{PF}$, paeoniflorin; UV, ultraviolet.

$12,000 \mathrm{x} \mathrm{g}$ for $15 \mathrm{~min}$, in order to remove nuclei and cell debris. Supernatants were then immediately frozen at $-80^{\circ} \mathrm{C}$, until further use. Protein concentrations were determined using the Bradford Assay (Bio-Rad Laboratories, Inc., Hercules, CA, USA) and $30 \mu$ g cellular proteins were separated by $10 \%$ SDS-polyacrylamide gel electrophoresis followed by electro-blotting onto polyvinylidene difluoride membranes (45 $\mu \mathrm{m}$; EMD Millipore, Billerica, MA, USA). The membranes were blocked for $1 \mathrm{~h}$ with $5 \%$ milk at room temperature, followed by an overnight incubation at $4^{\circ} \mathrm{C}$ with the following primary antibodies: P-p38, P-p53, p38, p53, cleaved caspase 3, caspase 3 and $\beta$-actin (all 1:1,000 dilution). Blots were washed twice with $0.1 \%$ Tween 20/Tris-buffered saline (TTBS) prior to incubation with a horseradish peroxidase-conjugated secondary antibody (1:1,000 dilution; Cell Signaling Technology, Inc.) for $1 \mathrm{~h}$ at room temperature. Blots were further washed with TTBS and were developed by enhanced chemiluminescence using Supersignal West Femto Chemiluminescent Substrate (Pierce; Thermo Fisher Scientific, Inc.). Band intensities were quantified using UN-SCAN-IT Gel 
A
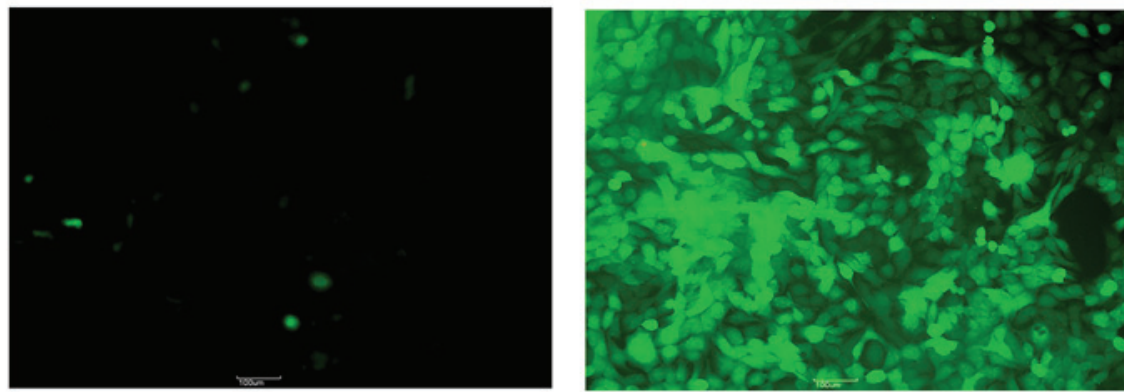

Medium

UV
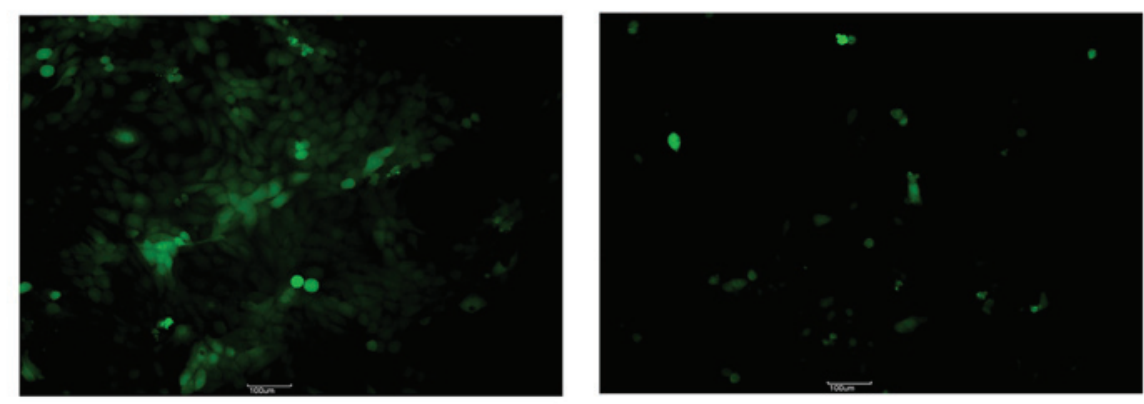

B

PF+UV

NAC+UV

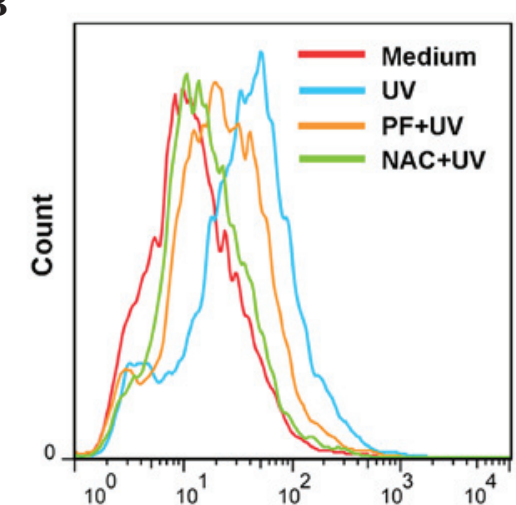

C

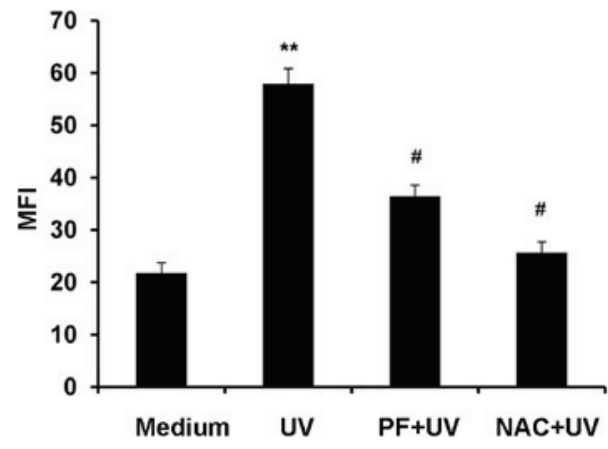

Figure 4. PF inhibited the production of ROS after UV-B radiation. For the ROS assay, cells were exposed to $25 \mu \mathrm{M}$ PF or $2 \mathrm{mM}$ NAC for $2 \mathrm{~h}$. After UV-B $\left(60 \mathrm{~mJ} / \mathrm{cm}^{2}\right)$ radiation, the cells were incubated for $6 \mathrm{~h}$ and were then treated with 2,-7,-dichlorofluorescein-diacetate $(10 \mu \mathrm{M})$. Following incubation at $37^{\circ} \mathrm{C}$ for $30 \mathrm{~min}$, the cells were washed with phosphate-buffered saline and fluorescence was monitored by flow cytometry or fluorescence microscopy. MFI data were analyzed using FlowJo software V6.0. (A) Representative fluorescence microscopy image of ROS (magnification x100). (B) Representative image of ROS MFI. (C) Statistical analysis of ROS MFI. Data are presented as the mean \pm standard deviation. ${ }^{* *} \mathrm{P}<0.01$, compared with the medium control group, ${ }^{\text {"P }}<0.01$, compared with UV-B exposure alone. PF, paeoniflorin; ROS, reactive oxygen species; UV, ultraviolet; NAC, N-acetyl-L-cysteine; MFI, mean fluorescence intensity.

Analysis software (version 6; Silk Scientific, Inc., Orem, UT, USA). The OD for target proteins was indicated as a proportion of $\beta$-actin OD. Western blotting was replicated three times.

Evaluation of ROS. ROS were detected using the cell-permeable fluorescent probe 2,-7,-dichlorofluorescein-diacetate ( $\mathrm{H}_{2} \mathrm{DCFDA}$ ) (Sigma-Aldrich), a non-fluorescent compound, which is converted into highly fluorescent dichlorofluorescein (DCF) by cellular peroxides. The cells were exposed to $25 \mu \mathrm{M}$ PF or $2 \mathrm{mM} \mathrm{NAC} \mathrm{for} 2 \mathrm{~h}$. Following radiation, the cells were incubated for a further $6 \mathrm{~h}$, after which, the cells were treated with $\mathrm{H}_{2}$ DCFDA $(10 \mu \mathrm{M})$ in serum-free DMEM. Following incubation at $37^{\circ} \mathrm{C}$ for $30 \mathrm{~min}$, the cells were washed with PBS and fluorescence was monitored by flow cytometry or fluorescence microscopy (DM1000; Leica Camera, Wetzlar, Germany). The mean fluorescence intensity (MFI) data were analyzed by FlowJo software V6.0 (Tree Star, Inc.). The MFI data were replicated three times.
Statistical analysis. All data are presented as the mean \pm standard deviation. Data analysis was performed using SPSS version 20.0 (IBM SPSS, Amronk, NY, USA). Statistical significance was detected using one-way analysis of variance. For comparisons between two groups, Student's t-test was used. $\mathrm{P}<0.05$ was considered to indicate a statistically significant difference.

\section{Results}

$P F$ attenuates $U V$-B-induced decreased cell viability in HaCaT cells. Cell viability was evaluated using the WST-8 assay. Exposure of HaCaT cells to UV-B resulted in a significant reduction in the percentage of viable cells (45\%) at $24 \mathrm{~h}$, as compared with the medium control group $(\mathrm{P}<0.01)$. Treatment with PF $(25,50$ or $100 \mu \mathrm{M})$ alone did not affect cell viability; however, cells pretreated with $\mathrm{PF}$ $(25,50$, and $100 \mu \mathrm{M})$ prior to UV-B radiation exhibited a 
A

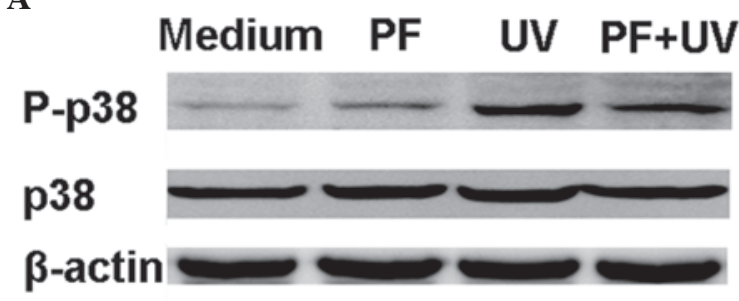

C

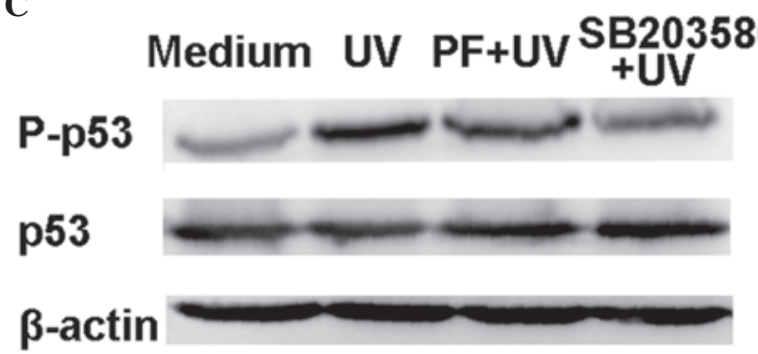

B

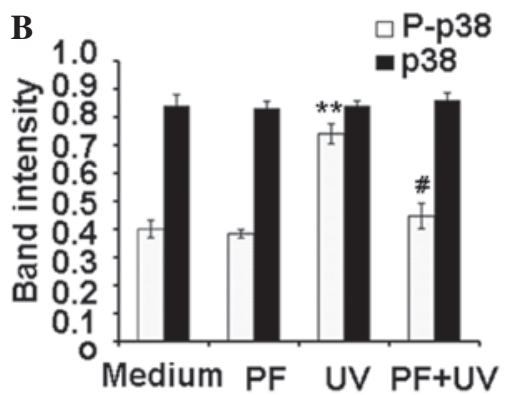

D

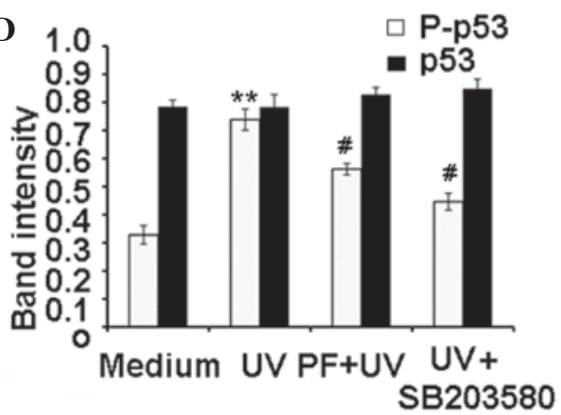

Figure 5. PF inhibited UV-B induced activation of $\mathrm{p} 38$ and p53. For western blotting, the cells were pretreated with $25 \mu \mathrm{M}$ PF or $5 \mu \mathrm{M}$ SB203580 for $2 \mathrm{~h}$. Following UV-B radiation, the cells were incubated for $24 \mathrm{~h}$. Total protein was extracted, and P-p38, p38, P-p53 and p53 expression levels were detected by western blot analysis. $\beta$-actin was used as a loading control. (A) Representative western blot of P-p38 and p38. (B) Quantification of band intensities of P-p38 and p38. (C) Representative western blot of P-p53 and p53. (D) Quantification of band intensities of P-p53 and p53. Band intensities were quantified using UN-SCAN-IT gel analysis software. Data are presented as the mean \pm standard deviation. ${ }^{* *} \mathrm{P}<0.01$, compared with the medium control; ${ }^{*} \mathrm{P}<0.01$, compared with UV-B exposure alone. PF, paeoniflorin; UV, ultraviolet; P, phosphorylated.

significant increase in the percentage of viable cells $(60 \%)$ No dose-dependent effects were observed following PF treatment (Fig. 1B).

PF reduces $U V$-B-induced cell death in HaCaT cells. It is well known that UV-B exposure induces apoptosis. As demonstrated by flow cytometry, UV-B $\left(60 \mathrm{~mJ} / \mathrm{cm}^{2}\right)$ radiation significantly increased cell death $(9.45 \%)$ at $24 \mathrm{~h}$, as compared with in the medium control group (2.58\%), whereas PF pretreatment markedly reduced UV-B-induced cell death (6\%) (Fig. 2A and B). Caspase 3 is expressed in an inactive pro-form, procaspase 3. In apoptosis, procaspase 3 is activated and generates two active subunits, cleaved caspase 3 (17). As shown in Fig. 3, UV radiation resulted in a significant decrease in the expression levels of procaspase 3 and an increase in cleaved caspase 3 expression. PF pretreatment partially counteracted the effects of UV-B on procaspase 3 and cleaved caspase 3 expression.

$P F$ inhibits the production of ROS after UV-B radiation. UV-B exposure results in the generation of ROS, which induce cell damage. The MFI of DCF was used to evaluate the production of ROS. As shown in Fig. 4, ROS production was significantly increased following UV-B radiation. Pretreatment with $25 \mu \mathrm{M}$ PF or $2 \mathrm{mM}$ NAC (a ROS scavenger), markedly inhibited the production of ROS after UV-B radiation.

$P F$ inhibits $U V$-B-induced activation of $p 38$ and $p 53$ in $\mathrm{HaCaT}$ cells. The activation of p38 and p53 is associated with UV-B-induced cell damage. Western blotting (Fig. 5) demonstrated that UV-B radiation significantly increased the expression levels of P-p38 and P-p53. Conversely, PF pretreatment markedly reduced the expression levels of P-p38 and
P-p53 following UV-B-radiation. Both UV radiation and PF pretreatment did not alter the expression levels of total p38 and p53. It has previously been reported that $\mathrm{p} 38$ kinase mediates UV-induced phosphorylation of p53 protein (10). As shown in Fig. 5C and D, SB203580, a p38 inhibitor, significantly reduced the expression levels of P-p53 after UV-B radiation.

\section{Discussion}

$\mathrm{UV}$ radiation is one of the most harmful environmental factors that contribute to skin damage (18). UV exposure induces extensive generation of ROS (19), which react with DNA, proteins and fatty acids, resulting in photoaging and skin cancer (20). One approach to protecting human skin against UV radiation is the use of antioxidants $(21,22)$. In recent years, naturally occurring herbal compounds have gained considerable attention as protective agents for UV exposure (19,23-25).

$\mathrm{PF}$ is a novel natural antioxidant, which is isolated from peony root $(26,27)$. The present study evaluated the protective effects of PF on UV-induced skin damage. The results demonstrated that treatment with PF significantly increased the percentage of viable keratinocytes following UV-B exposure. It is well known that UV-B exposure induces apoptosis, and caspase 3 has an important role in the execution of apoptosis (17). Cell death analysis in the present study revealed that PF treatment markedly reduced UV-B radiation-induced apoptosis in keratinocytes, which was accompanied by increased procaspase 3 expression and decreased cleaved caspase 3 expression, as compared with the UV-B radiation group.

The ROS-p38-p53 pathway is involved in UV-B-induced skin damage; oxidative stress induced by ROS can initiate MAPK signaling by phosphorylation of MAPK proteins. p38 
acts as a stress-activated MAPK that is preferentially activated by UV-generated ROS (9). In the present study, treatment with PF substantially reduced the production of ROS following exposure to UV. The UV-induced phosphorylation of p38 was also significantly inhibited by PF. Activation of p53 is important in cells with DNA damage caused by UV radiation $(4,7)$. It has previously been reported that p38 mediates UV-induced phosphorylation of p53 (10). In the present study, treatment with PF significantly reduced the production of ROS, and inhibited the activation of p38 and p53 in human keratinocytes. In addition, NAC, a ROS scavenger, and SB203580, a p38 inhibitor, significantly inhibited UV-B-induced decreased cell viability in human keratinocytes (data not shown). These results further demonstrate that the ROS-p38-p53 pathway is involved in UV-induced skin damage.

Numerous studies suggest that the activation of nuclear factor-E2-related factor 2(Nrf2) protects cutaneous keratinocytes and fibroblasts against the cytotoxic effects of UV (28-31). Nrf2 has emerged as a promising molecular target for the pharmacological prevention of skin damage caused by solar UV exposure. PF has been reported to protect radiation-induced pulmonary endothelial cells injury through the Nrf2 pathway (32). Further studies are, therefore, required in order to investigate the role of Nrf2 in the anti-UV effects of PF.

In conclusion, the present study reported that $\mathrm{PF}$ is able to attenuate UV-B-induced cell damage in human keratinocytes. Notably, the present study confirmed that these effects were mediated, at least in part, via inhibition of the ROS-p38-p53 pathway. Further studies are required to investigate the in vivo anti-UV effects of PF.

\section{Acknowledgements}

The present study was funded by grants from the National Natural Science Foundation of China (no. 81102541), Shanghai Municipal Commission of Health and Family Planning (grant no. 201440336) and the Scientific Research Project supported by Huashan Hospital, Fudan University (no. 2014QD09).

\section{References}

1. de Gruijl FR: Photocarcinogenesis: UVA vs. UVB radiation. Skin Pharmacol Appl Skin Physiol 15: 316-320, 2002.

2. Tyrrell RM: Ultraviolet radiation and free radical damage to skin. Biochem Soc Symp 61: 47-53, 1995.

3. Johnson BE: Formation of thymine containing dimers in skin exposed to ultraviolet radiation. Bull Cancer 65: 283-297, 1978.

4. Renzing J, Hansen S and Lane DP: Oxidative stress is involved in the UV activation of p53. J Cell Sci 109: 1105-1112, 1996.

5. Jurkiewicz BA and Buettner GR: Ultraviolet light-induced free radical formation in skin: An electron paramagnetic resonance study. Photochem Photobiol 59: 1-4, 1994.

6. Darzynkiewicz Z, Zhao H, Halicka HD, Rybak P, Dobrucki J and Wlodkowic D: DNA damage signaling assessed in individual cells in relation to the cell cycle phase and induction of apoptosis. Crit Rev Clin Lab Sci 49: 199-217, 2012.

7. Lee $\mathrm{CH}, \mathrm{Wu} \mathrm{SB}$, Hong $\mathrm{CH}$, Yu HS and Wei $\mathrm{YH}$ : Molecular mechanisms of UV-induced apoptosis and its effects on skin residential cells: The implication in UV-based phototherapy. Int J Mol Sci 14: 6414-6435, 2013.

8. Bae JY, Choi JS, Choi YJ, Shin SY, Kang SW, Han SJ and Kang YH: (-)Epigallocatechin gallate hampers collagen destruction and collagenase activation in ultraviolet-B-irradiated human dermal fibroblasts: Involvement of mitogen-activated protein kinase. Food Chem Toxicol 46: 1298-1307, 2008.
9. Johnson GL and Lapadat R: Mitogen-activated protein kinase pathways mediated by ERK, JNK, and p38 protein kinases. Science 298: 1911-1912, 2002.

10. Huang C, Ma WY, Maxiner A, Sun Y and Dong Z: p38 kinase mediates UV-induced phosphorylation of p53 protein at serine 389. J Biol Chem 274: 12229-12235, 1999.

11. Ganceviciene R, Liakou AI, Theodoridis A, Makrantonaki E and Zouboulis CC: Skin anti-aging strategies. Dermatoendocrinol 4: 308-319, 2012.

12. He DY and Dai SM: Anti-inflammatory and immunomodulatory effects of Paeonia lactiflora pall., a traditional Chinese herbal medicine. Front Pharmacol 2: 10, 2011.

13. Kim SH, Lee MK, Lee KY, Sung SH, Kim J and Kim YC: Chemical constituents isolated from Paeonia lactiflora roots and their neuroprotective activity against oxidative stress in vitro. J Enzyme Inhib Med Chem 24: 1138-1140, 2009.

14. Wankun X, Wenzhen Y, Min Z, Weiyan Z, Huan C, Wei D, Lvzhen $\mathrm{H}, \mathrm{Xu} \mathrm{Y}$ and Xiaoxin L: Protective effect of paeoniflorin against oxidative stress in human retinal pigment epithelium in vitro. Mol Vis 17: 3512-3522, 2011.

15. Wang H, Zhou H, Wang CX, Li YS, Xie HY, Luo JD and Zhou Y: Paeoniflorin inhibits growth of human colorectal carcinoma HT 29 cells in vitro and in vivo. Food Chem Toxicol 50: 1560-1567, 2012.

16. Lee S, Lim JM, Jin MH, Park HK, Lee EJ, Kang S, Kim YS and Cho WG: Partially purified paeoniflorin exerts protective effects on UV-induced DNA damage and reduces facial wrinkles in human skin. J Cosmet Sci 57: 57-64, 2006.

17. Bratton SB, MacFarlane M, Cain K and Cohen GM: Protein complexes activate distinct caspase cascades in death receptor and stress-induced apoptosis. Exp Cell Res 256: 27-33, 2000.

18. Kligman LH: Prevention and repair of photoaging: Sunscreens and retinoids. Cutis 43: 458-465, 1989.

19. Erden Inal M, Kahraman A and Köken T: Beneficial effects of quercetin on oxidative stress induced by ultraviolet A. Clin Exp Dermatol 26: 536-539, 2001.

20. Goihman-Yahr M: Skin aging and photoaging: An outlook. Clin Dermatol 14: 153-160, 1996.

21. Tebbe B: Relevance of oral supplementation with antioxidants for prevention and treatment of skin disorders. Skin Pharmacol Appl Skin Physiol 14: 296-302, 2001.

22. Afaq F and Mukhtar H: Photochemoprevention by botanical antioxidants. Skin Pharmacol Appl Skin Physiol 15: 297-306, 2002.

23. Katiyar SK and Elmets CA: Green tea polyphenolic antioxidants and skin photoprotection (Review). Int J Oncol 18: 1307-1313, 2001.

24. Widyarini S, Spinks N, Husband AJ and Reeve VE: Isoflavonoid compounds from red clover (Trifolium pratense) protect from inflammation and immune suppression induced by UV radiation. Photochem Photobiol 74: 465-470, 2001.

25. Svobodová A, Psotová J and Walterová D: Natural phenolics in the prevention of UV-induced skin damage. A review. Biomed Pap Med Fac Univ Palacky Olomouc Czech Repub 147: 137-145, 2003.

26. Chen T, Guo ZP, Jiao XY, Zhang YH, Li JY and Liu HJ: Protective effects of peoniflorin against hydrogen peroxide-induced oxidative stress in human umbilical vein endothelial cells. Can J Physiol Pharmacol 89: 445-453, 2011.

27. Zhong SZ, ma SP and Hong ZY: Peoniflorin activates Nrf2/ARE pathway to alleviate the Abeta(1-42)-induced hippocampal neuron injury in rats. Yao Xue Xue Bao 48: 1353-1357, 2013 (In Chinese).

28. Saw CL, Huang MT, Liu Y, Khor TO, Conney AH and Kong AN: Impact of Nrf2 on UVB-induced skin inflammation/photoprotection and photoprotective effect of sulforaphane. Mol Carcinog 50: 479-486, 2011.

29. Schafer M and Werner S: Nrf2 - A regulator of keratinocyte redox signaling. Free Radic Biol Med 88: 243-252, 2015.

30. Dinkova-Kostova AT, Jenkins SN, Fahey JW, Ye L, Wehage SL, Liby KT, Stephenson KK and Wade KL: Protection against UV-light-induced skin carcinogenesis in SKH-1 high-risk mice by sulforaphane-containing broccoli sprout extracts. Cancer Lett 240: 243-252, 2006.

31. Wondrak GT, Cabello CM, Villeneuve NF, Zhang S, Ley S, Li Y, Sun Z and Zhang DD: Cinnamoyl-based Nrf2-activators targeting human skin cell photo-oxidative stress. Free Radic Biol Med 45: 385-395, 2008

32. Yu J, Zhu X, Qi X, Che J and Cao B: Paeoniflorin protects human EA.hy926 endothelial cells against gamma-radiation induced oxidative injury by activating the NF-E2-related factor 2 /heme oxygenase-1 pathway. Toxicol Lett 218: 224-234, 2013. 